\title{
Urological manifestations of the disease related to immunoglobulin G4
}

\author{
Manifestaciones urológicas de la enfermedad relacionada con la inmunoglobulina G4
}

Luis Daniel Carrillo-Córdova ${ }^{1 *}$, Carlos Alberto Carrillo-Córdova ${ }^{1}$, Johnatan Vitar-Sandoval', Jorge Jaspersen-Álvarez ${ }^{2}$, Elba Luz Villena-López ${ }^{3}$ and Raúl Carrillo-Esper ${ }^{4}$

${ }^{1}$ Department of Urology, Hospital General de México Dr. Eduardo Liceaga; ${ }^{2}$ Faculty of Medicine, Universidad Nacional Autónoma de México; ${ }^{3}$ Department of Internal Medicine, Hospital Ángeles del Pedregal; ${ }^{4}$ Critical Areas Division CENIAQ, Instituto Nacional de Rehabilitación. Mexico City. Mexico

\begin{abstract}
Immunoglobulin G4 related disease (IgG4-RD) is a fibro-inflammatory disease of unknown etiology, characterized by lesions in the form of tumors, elevated serum IgG4 levels, plasma cells with significant IgG4 infiltration, accompanied by phlebitis obliterans and fibrosis. This disease usually has multiorgan disease, including pancreas, biliary tract, salivary glands, peri orbital tissues, kidneys, lungs, lymph nodes and retro peritoneum. IgG4-RD mainly affects men with a predominance of age by young adults until old age. The clinical manifestations of IgG4-RD, depend mainly on the organs affected and the response to steroids. His forecast is not yet clear. Within the affected urogenital organs can be observed kidney, retroperitoneum, ureter, bladder, urachus, testis/epididymis, paratesticular region, prostate and urethra.
\end{abstract}

KEY WORDS: IgG4-related disease. Retroperitoneal fibrosis. Urology.

\section{Resumen}

La enfermedad relacionada con la inmunoglobulina G4 (ER-IgG4) es una enfermedad fibroinflamatoria de etiología desconocida, la cual se caracteriza por presentar lesiones en forma de tumoraciones, concentraciones séricas aumentadas de IgG4 y células plasmáticas con una infiltración importante de lgG4, junto con flebitis obliterante y fibrosis. Esta enfermedad suele tener afección multiorgánica, incluyendo el páncreas, el tracto biliar, las glándulas salivares, los tejidos periorbitarios, Ios riñones, los pulmones, los ganglios linfáticos y el retroperitoneo. La ER-IgG4 afecta principalmente a hombres, con un predominio de edad por los adultos jóvenes y hasta la vejez. Las manifestaciones clínicas de la ER-IgG4 dependen principalmente de los órganos afectados y de la respuesta a los esteroides. Su pronóstico aún no es del todo claro. Dentro de los órganos urogenitales afectados pueden incluirse el riñón, el retroperitoneo, el uréter, la vejiga, el uraco, el testículo/epidídimo, la región paratesticular, la próstata y la uretra.

PALABRAS CLAVE: Enfermedad por IgG4. Fibrosis retroperitoneal. Urología.

\footnotetext{
Correspondence:

*Luis Daniel Carrillo-Córdova

Cerro Teponaxtle, 109

Col. Campestre Churubusco, Del. Coyoacán

C.P. 04200, Ciudad de México, México

E-mail: Carrillocor@gmail.com
}

Date of reception: 08-02-2017

Date of acceptance: $17-08-2017$

DOI: 10.24875/CIRUE.M18000009
Cir Cir. 2018;86:57-64

Contents available at PubMed www.cirugiaycirujanos.com 


\section{Introduction}

Immunoglobulin G4-related disease (IgG4-RD) is a chronic fibrotic inflammation, characterized by the presence of tissue lymphocytic infiltration, IgG4-positive plasma cells, development of fibrosis and sometimes increased serum IgG4 concentrations ${ }^{1,2}$. This disease usually affects multiple organs. Early diagnosis is very difficult to establish owing to the asymptomatic evolution of the disease at early stages and, when symptoms are present, these are vague and unspecific. The main manifestation is usually secondary to inflammation or fibrosis of a specific organ, causing direct damage to it. It can also be incidentally found during the diagnostic workup of a tumor when taking a biopsy. At all its stages, this disease usually responds well to steroid therapy ${ }^{3,4}$.

The kidney is one of the most commonly affected organs in IgG4-RD, and renal lesions are encompassed in a spectrum called IgG4-RD-associated kidney disease $^{4-8}$. As in some diseases that affect other organs, patients are asymptomatic or have vague and unspecific symptoms. However, approximately half of these patients will progress to kidney failure ${ }^{9}$. This shows the need to establish an early diagnosis, in order to initiate treatment in a timely manner. Renal lesions are distributed from the renal parenchyma to the pelvis and ureter ${ }^{3,9-16}$.

The most representative lesion among renal parenchymal lesions is tubulointerstitial nephritis rich in plasma cells, accompanied by infiltrates of IgG4-rich plasma cells and fibrosis, similar to that observed in the retroperitoneum ${ }^{7,9}$.

\section{Pathophysiology}

The disease is believed to have an allergic background and is mediated by the immune system, with abnormal immune responses being found. Adequate response to steroid therapy supports the immune etiology of this disease. Approximately $30-50 \%$ of patients have a history of allergies, eosinophilia or IgE increased serum levels ${ }^{17,18}$.

Patients with IgG4-RD have up-regulated responses to Th2 (interleukin [IL] 4, IL-5, IL-13 and IL-21) and regulatory $\mathrm{T}$ cells (IL-10 and tumor growth factor B1). The Th2 response induces an allergic response mediated by the immune system with eosinophilia and elevated $\lg \mathrm{E}^{19-22}$. Activated mast cells, highly positive for $\mathrm{lgE}$, promote the differentiation of naïve T-cells into

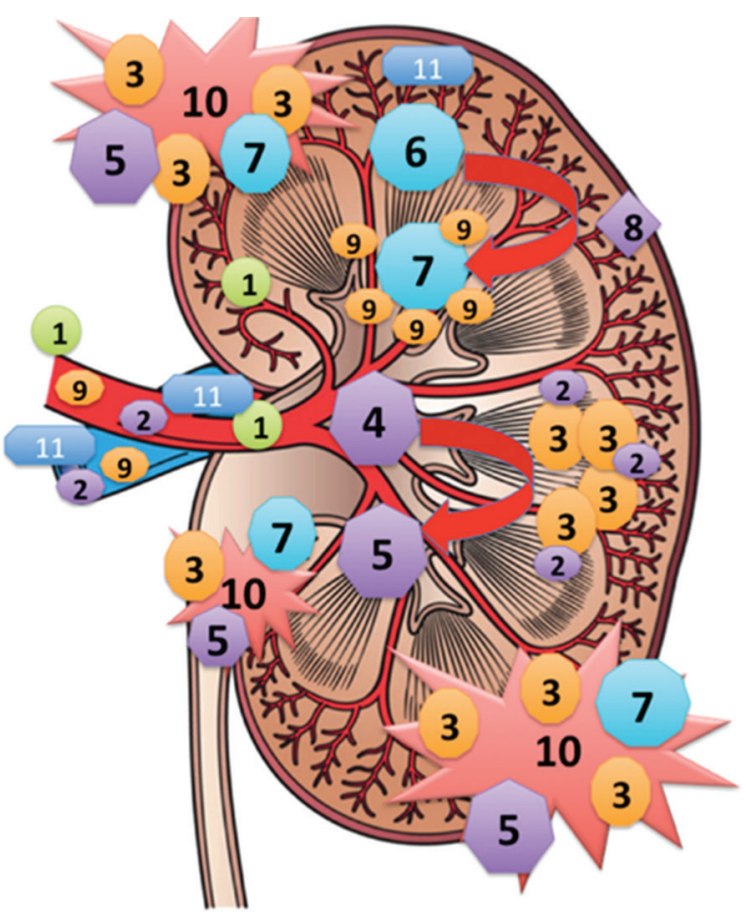

Figure 1. Pathophysiology of IgG4-related disease. Diagram showing the immune cells and interleukins involved. 1: eosinophils; 2: IgE; 3: activated mast cells; 4: naïve T-cell; 5: regulatory T-cell; 6: B-cell; 7: plasma cells; 8: IL-10; 9: IgG4; 10: lymphoid follicle; 11: plasmablast.

regulatory T-cells. IL-10 promotes B-cell differentiation into plasma cells, with subsequent IgG4production. IL-4 activates macrophages to produce high amounts of IL-10. IL-21, produced by follicular Th2 and T cells, is important for the formation of germinal centers and stimulates the production of IgG4 and plasma cells infiltration into tissues ${ }^{23,24}$. Monocytes cause massive infiltration of affected tissues, forming lymphoid follicles and producing the enlargement and deformation of affected tissues, which leads to their dysfunction; this infiltrate can give the appearance of a tumor in the kidney, renal pelvis or ureter ${ }^{25}$.

Antigen-induced circulating plasma cells have the phenotypes CD38+, CD27+, CD19+, CD20- and CD22- (short-lived plasmablasts). IgG4-RD is associated with an elevated plasmablast blood concentration, even in patients with normal serum IgG4. The plasmablast count is higher than that of IgG4 serum concentration as a biomarker for the diagnosis of $\lg$ G4-RD, and is useful for monitoring the disease and for predicting relapses ${ }^{26-28}$ (Fig. 1).

\section{Epidemiology}

In Japan, prevalence is estimated at 0.8 cases per 100,000 population, and the estimated incidence is 


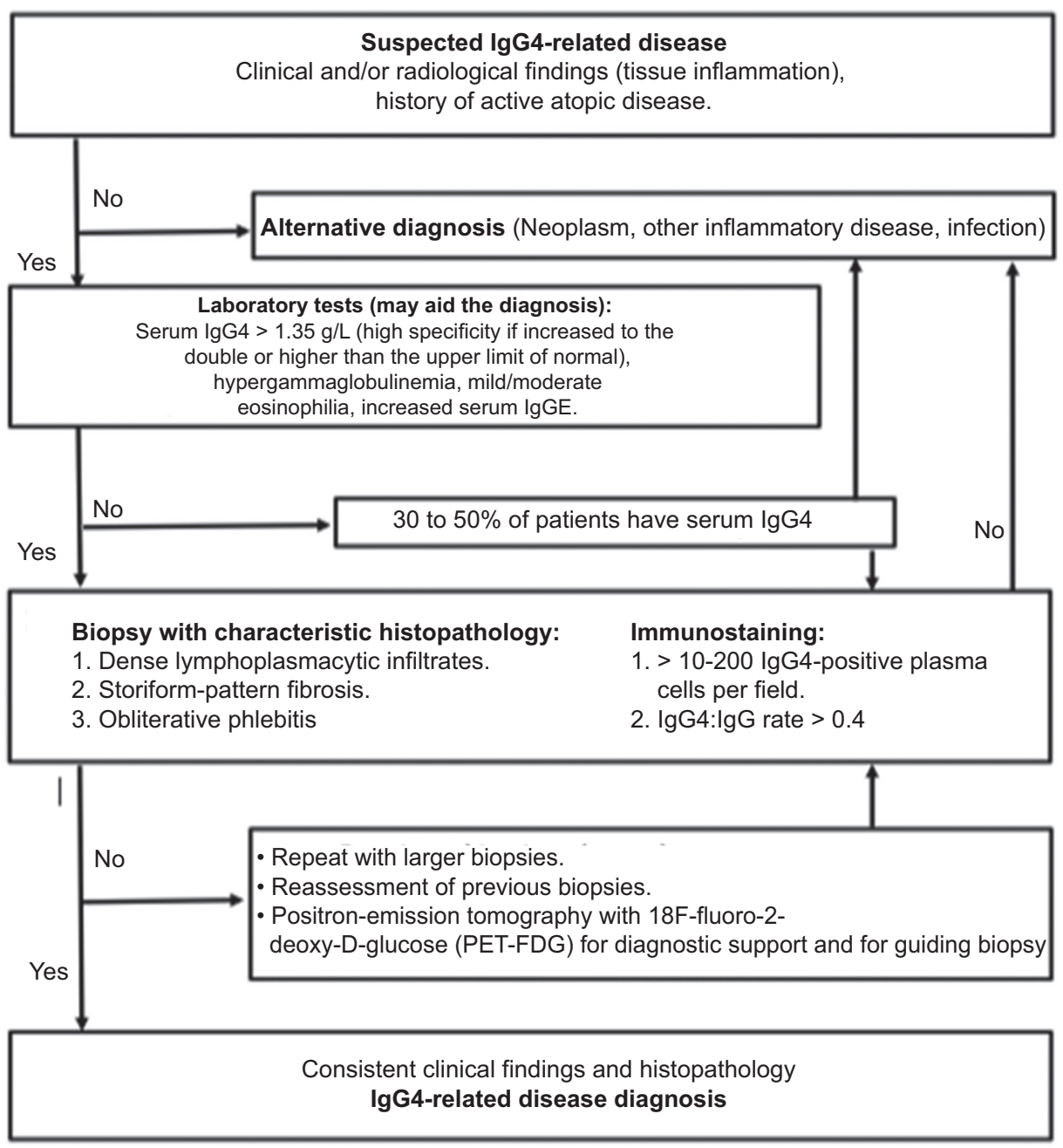

Figure 2. IgG4-related disease diagnostic algorithm. The diagnostic approach proposed by Umehara et al..$^{36}$ is shown.

0.28 to $1.08 / 100,000$, with $336-1300$ patients diagnosed every year and $6700-26,000$ patients who developed IgG4-RD in the past 20 years ${ }^{29}$. Another study estimated that the prevalence is $6 / 100,000$ population $^{30}$. This disease mainly affects males $(73-80 \%)$; with the only exception of manifestations in the head and neck, average age of presentation ranges from 50 to 60 years $^{31,32}$. There are some cases in the literature where this disease has been diagnosed in children $^{33-35}$. There are no articles in Latin America studying the epidemiology of the disease.

\section{Diagnosis}

IgG4-RD diagnosis is established by integrating clinical findings, laboratory tests, typical histopathology and radiology, as several authors have proposed ${ }^{36-38}$ (Fig. 2).

One third of patients have a history of atopic disease, including asthma, allergic rhinitis, nasal polyps and atopic dermatitis; non-atopic patients may exhibit peripheral blood eosinophilia or elevated $\lg \mathrm{E}^{39}$. Patients with IgG4-RD have often presented with allergies (up to $57 \%$ in a cohort) ${ }^{40}$.

Patients usually do not exhibit general symptoms, such as fever, weight loss, night sweats or general malaise. Malignant tumors have been reported in $7.4 \%$ of patients with IgG4-RD. Extranodal marginal B-cell lymphoma can occur in ocular adnexa, salivary glands or dura mater within 5 years after the IgG4-RD diagnosis ${ }^{41-43}$.

Laboratory tests are usually normal, in some cases with elevated C-reactive protein, increased erythrocyte sedimentation rate, anemia, thrombocytosis, and eosinophilia. Serology may reveal elevated IgE, polyclonal hypergammaglobulinemia, hypocomplementemia $(21 \%$ of cases, especially when there is renal involvement owing to the disease), presence of antinuclear antibodies (16-50\%) and rheumatoid factor (20\%). An elevated IgG4 can help to establish the 
diagnosis; a cut-off value > $1.35 \mathrm{~g} / \mathrm{L}$ has shown sensitivity of $97 \%$ and specificity of $79.6 \%$ to diagnose IgG4-RD. However, 30-50\% of patients with IgG4-RD will have normal IgG4 serum values ${ }^{44-47}$.

Radiological studies can reveal renal, ureteral and pyelic pseudo-tumors, secondary to organ infiltration by lymphocytes and monocytes. These lesions show soft tissue attenuation and well-defined borders on tomography and, on magnetic resonance imaging, these lesions vary from isointense to hypointense at T2, with homogeneous enhancement, which reflects increased cellularity and fibrosis; in case of extrinsic compression of the ureter by retroperitoneal fibrosis (RPF), or intrinsic by a ureteral or pelvic pseudotumor, hydronephrosis may be present ${ }^{48}$.

Positron-emission tomography (PET) with 18F-fluorodeoxyglucose allows carrying out a mapping of sites with inflammation by marking areas with hypermetabolic activity, which helps to assess the extent of disease and monitor its response to treatment ${ }^{49}$.

Currently, the standard method for IgG4-RD diagnosis consists of characteristic histology and immunohistochemistry identification, which is the same regardless of the affected organ. At late stages of the disease, fibrosis is the predominating feature, which makes the diagnosis more difficult ${ }^{50}$.

IgG4-RD three major features are: 1) dense lymphoplasmacytic infiltrates; 2) storiform fibrosis or in an irregular spiral pattern, similar to a straw mat; and 3) obliterating phlebitis. Sometimes, formation of germinal centers and infiltration by eosinophils in affected tissues is observed ${ }^{50}$. Immunohistochemistry for IgG4 shows plasma cell-rich infiltration; a number greater than 50 cells with positive IgG4 staining under a high power field is regarded as highly specific, but some other cut-off points have been proposed ${ }^{50}$. At more advanced stages of the disease, inflammation may have passed and fibrosis be predominant; in these cases, staining must be carried out for IgG-rich plasma cells. The IgG4/IgG ratio must be higher than 0.4 and is mandatory for IgG4-RD diagnosis ${ }^{50}$.

\section{Urological manifestations}

\section{Renal pseudo-tumor}

Renal pseudo-tumor is a lesion that mimics a renal carcinoma and is a very unusual form of presentation of the disease, with less than five cases reported in the literature to date ${ }^{51}$. It is difficult to differentiate between a renal pseudo-tumor secondary to IgG4-RD and a malignant lesion based only on imaging studies ${ }^{52}$. Renal ultrasound may show hypoechoic lesions or edema of the renal parenchyma, and tomography with intravenous contrast medium may reveal low-density single or multiple lesions ${ }^{53}$.

Magnetic resonance imaging can show isointense or hypointense renal tumors at $\mathrm{T} 1$, and hypointense images at $\mathrm{T} 2$, and show homogenous enhancement after contrast medium administration ${ }^{53}$. Definitive differential diagnosis will be provided by a biopsy, and treatment will be based on corticosteroids, by means of which the lesion will significantly improve, thus increasing renal function and decreasing circulating IgG4 concentration ${ }^{51}$.

\section{Pseudo-tumors of the renal pelvis and ureter}

IgG4-RD can occur as a single lesion in the renal pelvis or the ureter, causing filling defects and mimicking an urothelial carcinoma. There are only four cases reported in the literature ${ }^{54-57}$. Most cases that have reported renal or ureteral lesions are accompanied by synchronous or metachronous lesions in other organs ${ }^{56}$. Urinalysis in these patients usually shows moderate abnormalities. The appearance of these lesions in imaging studies is the same as that of renal pseudo-tumors, but in case the pseudotumor causes obstruction of the urinary tract, there will be renoureteral colic and hydronephrosis.

Tomographic findings reported for pseudo-tumors of the renal pelvis and ureter include hydronephrosis, ureteropelvic junction tumor and ureteral tumor. T1 isointense lesions and T2 hypointense lesions have been reported in magnetic resonance imaging. PET has shown an elevated glucose metabolism ${ }^{54,55,57}$. Management of these lesions is based on steroids, although due to their similarity to urothelial carcinoma, it is common for nephroureterectomy to be performed with a bladder swab, with the IgG4-RD diagnosis being established when the surgical specimen is examined ${ }^{54,57}$.

There is one case of ureteral pseudo-tumor reported in the literature ${ }^{58}$, which manifested itself with hydronephrosis, thickening of the ureteral wall and renal function deterioration. Nephroureterectomy was performed and final diagnosis was provided by analysis of the pathological specimen. Subsequent management with steroids was given and an important improvement in renal function was achieved. 


\section{Retroperitoneal fibrosis}

RPF clinical presentation can occur with vague abdominal and lower back pain, accompanied by nonspecific symptoms such as fever, myalgia, anorexia and weight loss. However, half the patients remain asymptomatic and, as the disease progresses, extrinsic compression of the ureter can lead to renal function loss, as well as to hydronephrosis; ureteral obstruction is found in $60-80 \%$ of patients with RPF secondary to IgG4-RD ${ }^{59,60}$.

RPF diagnosis is based on radiological findings and biopsy. IgG4 serum concentrations may or may not be elevated. Kidney ultrasound can provide valuable information about the degree of obstruction in the ureter and kidneys. Computed tomography and magnetic resonance imaging can provide useful information on the extent of disease.

Some authors have proposed to classify RPF in IgG4-RD as: 1) RPF; 2) inflammatory aneurysm of the abdominal aorta; 3) a combination of RPF and aneurysm; and 4) thoracic aortitis ${ }^{61-63}$.

The management of RPF includes urgent obstruction relief by means of nephrostomy or ureteral stent. Patients with urinary tract mild obstruction can be closely monitored while on steroid therapy. Definitive management of this condition is with the use of steroids ${ }^{62,63}$.

\section{Vesical pseudo-tumors}

There are only three cases of vesical pseudo-tumor documented in the literature, and in one of them, an inflammatory pseudo tumor of the bladder related to IgG4-RD was reported. Clinical presentation included asymptomatic gross hematuria, anemia and elevated serum IgG. Urinalysis revealed bacteriuria, hematuria, fecaluria and proteinuria. A tomography showed a tumor dependent on the bladder lateral wall with adhesion to the colon. The patient underwent partial cystectomy with resection of the affected part of the colon, with histopathologic finding of IgG4-RD. Definitive treatment was with steroid-based therapy ${ }^{64-66}$.

\section{IgG4-RD localization in the urachus}

There is one case reported in the literature of urachal disease due to IgG4-RD, which mimicked an urachal adenocarcinoma, managed with partial cystectomy. The histopathology report confirmed the IgG4-RD diagnosis by showing dense lymphoplasmacytic infiltration with IgG4-positive cells, fibrosis
Table 1. Urogenital tract organs involvement and number of reported cases

\begin{tabular}{lc}
\hline Affected organ & N \\
\hline Kidney & 76 \\
Retroperitoneum & 19 \\
Ureter & 7 \\
Bladder & 3 \\
Urachus & 1 \\
Testicle/epididymis & 2 \\
Paratesticular region & 6 \\
Prostate & 22 \\
Urethra & 5 \\
\hline
\end{tabular}

and phlebitis obliterans. IgG4 serum values were $227 \mathrm{mg} / \mathrm{dL}^{67}$.

\section{Pseudo-tumor of the urethra}

In 2012, the first case of IgG4-RD with presentation in the urethra was reported, which was found by tomography in a female patient with acute abdominal pain. A biopsy of the lesion was obtained, which revealed IgG4-RD. Patient history included an autoimmune pancreatitis diagnosis 17 years earlier. Treatment with steroids was given, with an important improvement of the condition being achieved. ${ }^{68}$

Another study reported an IgG4-RD prevalence of $11 \%$ in patients with urethral polyp diagnosis ${ }^{69}$.

\section{IgG4-RD-associated orchiepididymitis}

There have been reports of bilateral orchiepididymitis, accompanied by salivary glands involvement, with left testicle increased volume. Radical orchiectomy was performed owing to the suspicion of mycobacterial infection, with IgG4-RD being found during anatomopathological study. Serum IgG4 was $505 \mathrm{mg} / \mathrm{dL}$, with testicular and epididymal positive staining for $\lg G 4$, and with an $\lg G 4 / \lg$ ratio greater than $85 \%{ }^{70}$.

Another author ${ }^{71}$ reported a patient with orchitis complicated with testicular abscess, which was treated with radical orchiectomy, with pathological diagnosis confirming IgG4-RD.

\section{Paratesticular pseudo-tumors}

Some cases of IgG4-RD-related paratesticular pseudo-tumors have been reported in patients aged 19 to 52 years. On ultrasound, the appearance is the same as that of a paratesticular tumor, and diagnosis is suggested by patient history and steroid treatment response, or by surgical specimen results after definitive treatment ${ }^{72-74}$. 
Cirugía y Cirujanos. 2018;86

Table 2. Diagnostic criteria for tubulointerstitial nephritis due to IgG4-related disease

\begin{tabular}{ll}
\hline Histology & $\begin{array}{l}\text { Tubulointerstitial nephritis rich in plasma cells with more than } 10 \text { lgG4+ per high power field* } \\
\text { Deposit of immune complexes in the tubular basement membrane by immunohistochemistry or electron microscopy }\end{array}$ \\
$\begin{array}{l}\text { Imaging } \\
\text { Small peripheral cortical nodules, round or wedge-shaped lesions, or diffuse and irregular involvement }\end{array}$ \\
$\begin{array}{l}\text { Serology } \\
\text { Other organs involvement total lgG elevation, hypergammaglobulinemia, eosinophilia }\end{array}$ \\
$\begin{array}{l}\text { Autoimmune pancreatitis, sclerosing cholangitis, inflammatory masses in any organ, aortic aneurysm, lung involvement, } \\
\text { rMandatory criterion. } \\
\text { rSupport criterion in more than } 80 \% \text { of cases. }\end{array}$
\end{tabular}

\section{IgG4-RD-related prostatitis}

Numerous cases of IgG4-RD-associated prostatitis have been reported and, in most of them, it is accompanied by lower urinary tract symptoms, in patients within an age range of 55-73 years ${ }^{75}$. These patients have also been reported to usually have increased IgG4 serum levels $(499-1550 \mathrm{mg} / \mathrm{dL})^{75-77}$ and significant lymphoplasmacytic infiltration of the prostate. Definitive diagnosis is by means of prostate biopsy.

It is important for the urologist to know this etiology in order to avoid giving patients unnecessary treatments. An excellent response has been observed after treatment with steroids, although some patients have shown great symptom improvement after transurethral resection of the prostate $e^{75-81}$.

\section{Tubulointerstitial nephritis}

Kidney lesion clinical manifestation can be variable, either with the appearance of pseudo-tumors, acute or chronic kidney injury or proteinuria associated with glomerular disease. The causes of tubulointerstitial nephritis are determined by biopsy together with patient clinical history, physical examination, serum markers and imaging studies. Tubulointerstitial nephritis secondary to IgG4-RD is reported as an autoimmune tubulointerstitial nephritis. It is IgG4-RD most common renal manifestation. Eighty-five percent of patients show radiographic abnormalities, in $81 \%$ with elevated $\operatorname{lgG}$ or IgG4 serum concentrations, and $28 \%$ with eosinophilia. It is more common to find acute or chronic kidney lesion than the appearance of pseudo-tumors. Eighty-four percent of these patients have autoimmune complexes deposits in the tubular basement membrane, where there is also a granular pattern for $\lg G$, C3, and kappa and lambda light chains.

Table 1 summarizes all urological manifestations and the number of cases thus far reported. IgG4-RD diagnostic criteria are listed in table $2^{82,83}$.

\section{Treatment}

Recently, a guideline for the management of patients with IgG4-RD was created, but, even so, there is no definitive treatment, and it varies according to each patient.

Strategies that can be resorted to include:

- Watchful waiting strategy: it is the strategy of choice in asymptomatic patients. In case of kidney, ureter or bladder involvement, if this strategy is adopted, it is necessary for renal function to be frequently monitored and to perform serial ultrasounds in order to assess the morphology of the urinary tract. ${ }^{22,84}$

- Glucocorticoids: the response to low-dose steroids is distinctive IgG4-RD, although, interestingly, up to $30 \%$ of patients with IgG4-RD have spontaneous resolution and a similar percentage is refractory or experiences relapses.

- Other therapies: for those patients in whom steroid therapy does not work or, if relapse occurs, $\mathrm{B}$-cell depletion therapy with rituximab is generally adequate. We can also use methotrexate, mycophenolic acid and azathioprine. There is evidence that treatment modifies the natural course of disease, both to normalize organ function and to avoid fibrosis ${ }^{85-87}$.

\section{Conclusion}

IgG4-RD urological manifestations are many and can affect any genitourinary tract organ. It is important for the urologist to have knowledge of this disease, as well as of its clinical manifestations, its diagnostic criteria and its treatment, in order to offer better care to patients.

\section{Ethical responsibilities}

Protection of people and animals. The authors declare that no experiments have been conducted in humans or animals for this research. 
Confidentiality of data. The authors declare to have followed the protocols of their work center on the publication of patient data.

Right to privacy and informed consent. The authors declare that no patient data appear in this article.

\section{Funding}

The authors declare that there is no funding.

\section{Conflict of interests}

The authors declare that there are no conflicts of interests.

\section{References}

1. Kamisawa $T$, Funata $N$, Hayashi $Y$, et al. A new clinicopathological entity of IgG4- related autoimmune disease. J Gastroenterol. 2003;38:982-4.

2. Masaki $\mathrm{Y}$, Dong L, Kurose N, et al. Proposal for a new clinical entity, IgG4-positive multiorgan lymphoproliferative syndrome: analysis of 64 cases of IgG4-related disorders. Ann Rheum Dis. 2009;68:1310-5.

3. Kamisawa T, Shimosegawa T, Okazaki K, et al. Standard steroid treatment for autoinmune pancreatitis. Gut. 2009;58:1504-7.

4. Hart PA, Kamisawa T, Brugge WR, et al. Long-term outcomes of autoimmune pancreatitis: a multicentre, international analysis. Gut. 2013;62:1771-6.

5. Inoue D, Yoshida K, Yoneda N, et al. IgG4-related disease: dataset of 235 consecutive patients. Medicine (Balt). 2015;94:e680.

6. Wallace ZS, Deshpande V, Mattoo H, et al. IgG4-related disease: clinical and laboratory features in one hundred twenty-five patients. Arthritis Rheum (Munch). 2015;67:2466-75.

7. Kawano M, Saeki T, Nakashima H, et al. Proposal for diagnostic criteria for IgG4-related kidney disease. Clin Exp Nephrol. 2011;15:615-26.

8. Stone JH, Khosroshahi A, Deshpande V, et al. Recommendations for the nomenclature of IgG4-related disease and its individual organ system manifestations. Arthritis Rheum. 2012;64:3061-7.

9. Raissian Y, Nasr SH, Larsen CP, et al. Diagnosis of IgG4-related tubulointerstitial nephritis. J Am Soc Nephrol. 2011;22:1343-52.

10. Takahashi N, Kawashima A, Fletcher JG, Chari ST. Renal involvement in patients with autoimmune pancreatitis: CT and MR imaging findings. Radiology. 2007;242:791-801.

11. Inoue D, Kawano M, Yamada K. Kidney and urinary tract lesions. En: Umehara H, Okazaki K, Stone JH, Kawa S, Kawano M, editores. IgG4-related disease. Tokyo: Springer Japan; 2014. p. 99-105.

12. Kim SA, Lee SR, Huh J, et al. IgG4-associated inflammatory pseudotumor of ureter: clinicopathologic and immunohistochemical study of 3 cases. Hum Pathol. 2011;42:1178-84.

13. Abe $H$, Morikawa $T$, Araki A, et al. IgG4-related periureteral fibrosis presenting as a unilateral ureteral mass. Pathol Res Pract. 2011; 207:712-14.

14. Kim S, Kim TG, Choi SK, et al. Immunoglobulin G4-related systemic sclerosing disease: a case involving the ureter and kidney. Korean $\mathrm{J}$ Urol. 2013;54:209-11.

15. Marando A, D'Ambrosio G, Catanzaro F, et al. IgG4-related disease of the ureter: report of two cases and review of the literature. Virchows Arch. 2013;462:673-8.

16. Moriarty MA, Dahmoush L, Nepple KG. IgG4 related disease of the ureter (inflammatory pseudotumor). J Urol. 2014;191:1126-7.

17. Della Torre E, Mattoo H, Mahajan VS, et al. Prevalence of atopy, eosinophilia, and IgE elevation in IgG4-related disease. Allergy. 2014;69: 269-72.

18. Chen $\mathrm{H}$, Lin W, Wang Q, et al. IgG4-related disease in a Chinese cohort: a prospective study. Scand J Rheumatol. 2014;43:70-4.

19. Nirula A, Glaser SM, Kalled SL, et al. What is IgG4? A review of the biology of a unique immunoglobulin subtype. Curr Opin Rheumatol. 2011; 23:119-24.

20. Tanaka A, Moriyama M, Nakashima $H$, et al. Th2 and regulatory immune reactions contribute to IgG4 production and the initiation of Mikulicz disease. Arthritis Rheum. 2012;64:254-63.

21. Tsuboi H, Matsuo N, lizuka M, et al. Analysis of IgG4 class switch-related molecules in IgG4-related disease. Arthritis Res Ther. 2012;14:R171.
22. Takeuchi M, Sato $\mathrm{Y}$, Ohno $\mathrm{K}$, et al. $\mathrm{T}$ helper 2 and regulatory T-cell cytokine production by mast cells: a key factor in the pathogenesis of IgG4-related disease. Mod Pathol. 2014;27:1126-36.

23. Shevach EM, DiPaolo RA, Andersson J, et al. The lifestyle of naturally occurring CD4+ CD25+ Foxp3+ regulatory T cells. Immunol Rev. 2006; 212:60-73.

24. Meiler F, Klunker S, Zimmermann M, et al. Distinct regulation of $\lg E$, IgG4 and IgA by T regulatory cells and toll-like receptors. Allergy. 2008; 63:1455-63.

25. Satoh-Nakamura T, Kurose N, Kawanami T, et al. CD14+ follicular dendritic cells in lymphoid follicles may play a role in the pathogenesis of IgG4-related disease. Biomed Res. 2015;36:143-53.

26. Medina F, Segundo C, Campos-Caro A, et al. The heterogeneity shown by human plasma cells from tonsil, blood, and bone marrow reveals graded stages of increasing maturity, but local profiles of adhesion molecule expression. Blood. 2002;99:2154-61.

27. Wallace ZS, Mattoo H, Carruthers M, et al. Plasmablasts as a biomarker for IgG4-related disease, independent of serum IgG4 concentrations. Ann Rheum Dis. 2015;74:190-5.

28. Mattoo H, Mahajan VS, Della-Torre E, et al. De novo oligoclonal expansions of circulating plasmablasts in active and relapsing IgG4-related disease. J Allergy Clin Immunol. 2014;134:679-87.

29. Umehara $H$, Okazaki K, Masaki $Y$, et al. A novel clinical entity, IgG4-related disease (IgG4RD): general concept and details. Mod Rheumatol/ Jpn Rheum Assoc. 2012;22:1-14.

30. Uchida K, Masamune A, Shimosegawa T, et al. Prevalence of IgG4-related disease in Japan based on nationwide survey in 2009. Int J Rheumatol. 2012;2012:358371.

31. Yamamoto M, Yajima H, Takahashi H, et al. Everyday clinical practice in IgG4- related dacryoadenitis and/or sialadenitis: results from the SMART database. Mod Rheumatol. 2015;25:199-204.

32. Wallace ZS, Deshpande V, Mattoo H, et al. IgG4-related disease: clinical and laboratory features in 125 patients. Arthritis Rheumatol. 2015;67:2466-75.

33. Mannion $M$, Cron $R Q$. Successful treatment of pediatric IgG4 related systemic disease with mycophenolate mofetil: case report and a review of the pediatric autoimmune pancreatitis literature. Pediatr Rheumatol Online J. 2011;9:1.

34. Laco J, Podhola M, Kamaradova K, et al. Idiopathic vs. secondary retroperitoneal fibrosis: a clinicopathological study of 12 cases, with emphasis to possible relationship to IgG4-related disease. Virchows Arch Int $\mathrm{J}$ Pathol. 2013;463:721-30.

35. Kalapesi FB, Garrott HM, Moldovan C, et al. IgG4 orbital inflammation in a 5-year old child presenting as an orbital mass. Orbit. 2013;32:137-40.

36. Umehara $\mathrm{H}$, Okazaki $\mathrm{K}$, Masaki $\mathrm{Y}$, et al. Comprehensive diagnostic criteria for IgG4-related disease (IgG4-RD), 2011. Mod Rheumatol. 2012; 22:21-30.

37. Kawano M, Saeki T, Nakashima $\mathrm{H}$, et al. Proposal for diagnostic criteria for IgG4- related kidney disease. Clin Exp Nephrol. 2011;15:615-26.

38. Shimosegawa T, Chari ST, Frulloni L, et al. International consensus diagnostic criteria for autoimmune pancreatitis: guidelines of the International Association of Pancreatology. Pancreas. 2011;40:352-8.

39. Della Torre E, Mattoo H, Mahajan VS, et al. Prevalence of atopy, eosinophilia, and IgE elevation in IgG4-related disease. Allergy. 2014;69: 269-72.

40. Chen $\mathrm{H}$, Lin W, Wang $\mathrm{Q}$, et al. IgG4-related disease in a Chinese cohort: a prospective study. Scand J Rheumatol. 2014;43:70-4.

41. Yamamoto $M$, Takahashi $H$, Shinomura $Y$. Mechanisms and assessment of IgG4-related disease: lessons for the rheumatologist. Nat Rev Rheumatol. 2014;10:148-59.

42. Cheuk W, Yuen HK, Chan AC, et al. Ocular adnexal lymphoma associated with IgG4+ chronic sclerosing dacryoadenitis: a previously undescribed complication of IgG4-related sclerosing disease. Am J Surg Pathol. 2008;32:1159-67.

43. Venkataraman G, Rizzo KA, Chavez JJ, et al. Marginal zone lymphomas involving meningeal dura: possible link to IgG4-related diseases. Mod Pathol. 2011;24:355-66.

44. Takahashi H, Yamamoto M, Tabeya $T$, et al. The immunobiology and clinical characteristics of IgG4 related diseases. J Autoimmun. 2012;39:93-6.

45. Kiyama K, Yoshifuji H, Kandou T. Screening for IgG4-type anti-nuclear antibodies in IgG4-related disease. BMC Musculoskelet Disord. 2015;16:129.

46. Masaki $Y$, Kurose N, Yamamoto $M$, et al. Cutoff values of serum IgG4 and histopathological IgG4+ plasma cells for diagnosis of patients with IgG4-related disease. Int J Rheumatol. 2012;2012:580814.

47. Carruthers MN, Khosroshahi A, Augustin T, et al. The diagnostic utility of serum IgG4 concentrations in IgG4-related disease. Ann Rheum Dis. 2015;74:14-8.

48. Katsura M, Mori H, Kunimatsu A, et al. Radiological features of IgG4-related disease in the head, neck, and brain. Neuroradiology. 2012;54:873-82.

49. Nakatani K, Nakamoto $Y$, Togashi K. Utility of FDG PET/CT in IgG4-related systemic disease. Clin Radiol. 2012;67:297-305.

50. Deshpande V, Zen Y, Chan JK, et al. Consensus statement on the pathology of IgG4-related disease. Mod Pathol. 2012;25:1181-92.

51. Cai Y, Li H-Z, Zhang Y-S. IgG4-related inflammatory pseudotumor of the kidney mimicking renal cell carcinoma: a case report. Oncology Letters. 2016;11:3438-40. 
52. Saeki T, Kawano M. IgG4-related kidney disease. Kidney Int. 2014;85:251-7.

53. Kuroda N, Nao T, Fukuhara H, et al. IgG4-related renal disease: clinical and pathological characteristics. Int J Clin Exp Pathol. 2014;7:6379-85.

54. Tan $\mathrm{TJ}, \mathrm{Ng} \mathrm{YL}$, Tan $\mathrm{D}$, et al. Extrapancreatic findings of IgG4 related disease. Clin Radiol. 2014;69:209-18.

55. Wang Y, Chen X, Luo R, et al. IgG4-related systemic disease mimicking renal pelvic cancer: a rare case. World J Surg Oncol. 2014;12:395.

56. Yoshino $\mathrm{T}$, Moriyama $\mathrm{H}$, Fukushima $\mathrm{M}$, et al. A case of IgG4-related retroperitoneal fibrosis mimicking renal pelvic cancer. Urol Int. 2012; 90:365-8.

57. Nishi S, Imai N, Yoshida K, et al. Clinicopathological findings of immunoglobulin G4-related kidney disease. Clin Exp Nephrol. 2011:15:810-9.

58. Park HG, Kim KM. IgG4-related inflammatory pseudotumor of the renal pelvis involving renal parenchyma, mimicking malignancy. Diagn Pathol. 2017;11:12.

59. Lei $\mathrm{WH}$, Xin J, Shao CX, et al. IgG4 related kidney disease mimicking malignant ureter tumor: case report and literature review. Medicine (Balt). 2016;95:e2550.

60. Hara N, Kawaguchi M, Takeda K, et al. Retroperitoneal disorders associated with IgG4-related autoimmune pancreatitis. World J Gastroenterol. 2014;20:16550-8.

61. Corradi D, Maestri R, Palmisano A, et al. Idiopathic retroperitoneal fibrosis: clinicopathologic features and differential diagnosis. Kidney Int. 2007;72:742-53.

62. Vaglio A, Salvarani C, Buzio C. Retroperitoneal fibrosis. Lancet. 2006 367:241-51.

63. Kottra JJ, Dunnick NR. Retroperitoneal fibrosis. Radiol Clin North Am. 1996;34:1259-75.

64. Zen Y, Kasashima S, Inoue D. Retroperitoneal and aortic manifestations of immunoglobulin G4-related disease. Semin Diagn Pathol. 2012;29:212-8.

65. Park S, Ro JY, Lee DH, et al. Immunoglobulin G4-associated inflammatory pseudotumor of urinary bladder: a case report. Ann Diagn Pathol. 2013;17:540-3.

66. Montironi R, Scarpelli M, Cheng L, et al. Immunoglobulin G4-related disease in genitourinary organs: an emerging fibroinflammatory entity often misdiagnosed preoperatively as cancer. Eur Urol. 2013;64:865-72.

67. Dropkin BM, Ingimarsson JP, Jones JD, et al. Immunoglobulin G4-related disease in the urinary bladder. Int J Urol. 2015;22:605-7.

68. Dum TW, Zhang D, Lee EK. IgG4-related disease in a urachal tumor. Case Rep Urol. 2014;2014:275850.

69. Choi JW, Kim SY, Moon KC, et al. Immunoglobulin G4-related sclerosing disease involving the urethra: case report. Korean J Radiol. 2012;13: 803-7.

70. Williamson SR, Scarpelli M, López-Beltran A, et al. Urethral caruncle: a lesion related to IgG4-associated sclerosing disease? J Clin Pathol. 2013;66:559-62.

71. Migita K, Miyashita T, Mizuno A, et al. IgG4-related epididymo-orchitis associated with bladder cancer: possible involvement of BAFF/BAFF-R interaction in IgG4-related urogenital disease. Mod Rheumatol. 2014; 24:188-94.

72. de Buy Wenniger LM, Scheltema JM, Verheij J, et al. Testicular inflammation as a new manifestation of IgG4-associated disease. Urology. 2013;82:e15-6.

73. Bösmüller $\mathrm{H}$, von Weyhern $\mathrm{CH}$, Adam $\mathrm{P}$, et al. Paratesticular fibrous pseudotumor — an IgG4- related disorder? Virchows Arch. 2011;458:109-13.

74. Karashima T, Taniguchi $Y$, Shimamoto $T$, et al. IgG4-related disease of the paratestis in a patient with Wells syndrome: a case report. Diagn Pathol. 2014;9:225.

75. Hart PA, Moyer AM, Yi ES, et al. IgG4-related paratesticular pseudotumor in a patient with autoimmune pancreatitis and retroperitoneal fibrosis: an extrapancreatic manifestation of IgG4-related disease. Hum Pathol. 2012;43:2084-7.

76. Yoshimura Y, Takeda S, leki Y, et al. IgG4-associated prostatitis complicating autoimmune pancreatitis. Intern Med. 2006;45:897-901.

77. Uehara $\mathrm{T}$, Hamano $\mathrm{H}$, Kawakami $\mathrm{M}$, et al. Autoimmune pancreatitis associated prostatitis: distinct clinicopathological entity. Pathol Int. 2008; 58:118-25.

78. Buijs J, de Buy Maillette, Wenniger L, et al. Immunoglobulin G4-related prostatitis: a case-control study focusing on clinical and pathologic characteristics. Urology. 2014;83:521-6.

79. Hart PA, Smyrk TC, Chari ST. IgG4-related prostatitis: a rare cause of steroid-responsive obstructive urinary symptoms. Int J Urol. 2013;20: $132-4$.

80. Nishimori I, Kohsaki T, Onishi S, et al. IgG4-related autoimmune prostatitis: two cases with or without autoimmune pancreatitis. Intern Med. 2007;46:1983-9.

81. Bourlon MT, Sánchez-Ávila M, Chablé-Montero F, et al. IgG4-related autoimmune prostatitis: is it an unusual or underdiagnosed manifestation of IgG4-related disease? Case Rep Urol. 2013;2013:295472.

82. Nakai $Y$, Kagebayashi $Y$, Matsumoto $Y$, et al. IgG4-related prostatitis associated with retroperitoneal fibrosis: a case report. Hinyokika Kiyo. 2013;59:781-4.

83. Saeki T, Nishi S, Imai N, et al. Clinicopathological characteristics of patients with IgG4-related tubulointerstitial nephritis. Kidney Int. 2010;78:1016-23.

84. Raissian Y, Nasr SH, Larsen CP, et al. Diagnosis of IgG4-related tubulointerstitial nephritis. J Am Soc Nephrol. 2011;22:1343-52.

85. Khosroshahi A, Wallace ZS, Crowe JL, et al. International consensus guidance statement on the management and treatment of IgG4-related disease. Arthritis Rheumatol. 2015;67:1688-99.

86. Khosroshahi A, Carruthers MN, Deshpande V, et al. Stone rituximab fo the treatment of IgG4-related disease: lessons from 10 consecutive patients. Medicine (Balt). 2012;91:57-66.

87. Vasaitis L. IgG4-related disease: a relatively new concept for clinicians. Eur J Intern Med. 2016;27:1-9. 